\title{
Paper 2005-1511 \\ Laboratories for the Design and Assembly of Electronic Devices using Surface Mount Components
}

\author{
Glenn R. Blackwell, P.E. \\ Purdue University \\ blackwell@purdue.edu
}

\begin{abstract}
Purdue's ECET department has supported surface mount technology (SMT) in its labs for over 10 years. In that time the department has expanded its teaching of the design and assembly of devices incorporating surface mount components (SMCs) from design basics and simple manual assembly in one undergraduate class, to more complex designs and manual \& automated assembly in two electronic manufacturing courses, one undergraduate and one dual-level. The students in the department routinely use Cadence electronic computer aided design (ECAD) software for the design and analysis of circuits and for the design of printed circuit boards (PCBs). The boards are fabricated by a commercial PCB fabricator, then assembled in one of two laboratories the department has with assembly equipment suitable for both manual and automated assembly of SMCs.
\end{abstract}

This paper will briefly discuss the design concepts unique to SMT devices and the manual and automated assembly technologies suitable for use in teaching laboratories. SMCs from chip resistor and capacitor components through fine-pitch quad flat pack ICs can be manually soldered and desoldered from PCBs with equipment costing no more than $\$ 800$. The paper will give examples of the manual tools necessary to perform these operations, as well as of semi-automated and fully-automated equipment suitable for SMC assembly, and ranging in cost from $\$ 6 \mathrm{~K}$ for semi-automated tools to $\$ 30 \mathrm{~K}$ for a small automated assembly line. The paper will also present examples of projects completed by students, as well as learning objectives for the undergraduate course.

\section{Introduction - why teach SMT?}

Consumers have demanded the proliferation of personal electronic devices and their continued reduction in size with a continued increase in performance. Many of the technology improvements that allow these continual changes are attributable to advances in two areas, those in semiconductor silicon fabrication and those in electronic component packaging. While the former technologies tend to get the most press, the latter technologies are used by far more companies and are more likely to get taught at the university level, since more graduates are likely to need a knowledge of packaging technologies in their employment. The author believes this is true since many graduates of technical programs will be involved in the design, manufacturing, testing and/or support of electromechanical devices, and these areas are better served by personnel with knowledge of electronic packaging and assembly processes. 
The packaging technology improvements have occurred for both passive devices such as resistors and capacitors as well as for active devices such as integrated circuits. Virtually all of the newer component packages are under the umbrella of surface mount technology (SMT), where the components mount on the surface of a printed circuit board (PCB) with no terminations (leads) that require holes in the board. Compared to older through hole technology (THT) components, size reductions are considerable. The passive devices have not changed their basic characteristics, only the external packaging sizes have been reduced to better suit the demands for smaller components.

SMT was developed by IBM and others in the 1960s and 1970s to reduce the size of electronic component packages and thereby reduce the size of devices designed with those packages $^{1,2}$. These technologies have other advantages for both design engineers and manufacturing engineers, including reduced package-related parasitics, with resulting improvements in high-speed performance, and allowing high-speed assembly automation. In 2002 worldwide production of integrated circuits (ICs) indicated that $86 \%$ of all ICs were produced in SMT packages. This number continues to rise, and leads to the conclusion that the basic concepts of SMT, design of SMT-based products using DFM principles, and the implementation of DFM principles in manufacturing must all be available in to students in higher education.

\section{SMT Undergraduate Course}

The students in Purdue's undergraduate ECET curriculum have had introductions to basic SMT components, and basic SMT assembly techniques in their required courses. Based on this background, the learning objectives for this undergraduate SMT course are:

- Demonstrate the principles of hand soldering of small surface mount parts.

- Describe standard SMT parts by both size and lead pitch.

- Describe automated surface mount assembly steps and their associated design requirements.

- Describe proper circuit board handling techniques with regard to ESD and EOS concerns.

- Describe the composition of solder paste, both leaded and lead-free, and explain how solder joint and the intermetallic layer are formed.

- Apply the principles of solder paste deposition and reflow soldering to create acceptable solder joints.

From these learning objectives, the course content is based on the following topics:

- SMT basics, in more detail than the students' earlier exposure.

- DFM for SMT, without which it is not possible to complete a good design.

- Manufacturing steps for SMT designs.

- Laboratory exercises, using standard SMT parts, tools, and machines.

\section{SMT Basics}

The basic differences between SMT and THT components are:

- SMT components are smaller

- SMT components mount to the surface of a PCB without the need for through holes.

"Proceedings of the 2005 American Society for Engineering Education Conference \& Exposition Copyright (C) 2005, American Society for Engineering Education" 
The first of these advantages reduces electronic product size simply by demanding less volume for a given component. The second of these advantages reduces product size by both reducing the size of the required circuit board and allowing more freedom in placing components since, unlike THT components, designer have the freedom to use both sides of the PCB without mechanical concerns for components on the opposite side. For instance, where the top of the board has a ball grid array (BGA) component, the bottom side of the board may have a corresponding set of chip decoupling capacitors. The pattern of pads for a given component on the circuit board is called that component's "footprint". The footprint can range from 2 pads for a resistor to in excess of 1000 pads for an ultra-large scale integrated circuit.

Along with these design advantages, manufacturing is also easier and faster with the use of SMT. Compared to THT components, that require insertion machines to line up all the component leads with all the corresponding holes in the PCB, SMT allows for much faster placement since placement is allowed that does not exactly line up component terminations and the corresponding pads on the PCB surface, as shown in figure 1. The example in figure 1 is based on IPC standard IPC-A-610, Revision C, January 2000, "Acceptability of Electronic Assemblies". It shows both target and acceptable placements for chip components, for the three classes of electronic assemblies. These classes are:

- Class 1: general/consumer electronic products

- Class 2: dedicated service electronic products where failure is highly undesirable but not critical, such as servers and telecomm products

- Class 3: high reliability products, where failure is considered unacceptable, such as life-support electronics and missile systems.

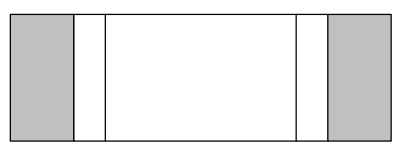

Target - Class $1,2,3$

No side overhang
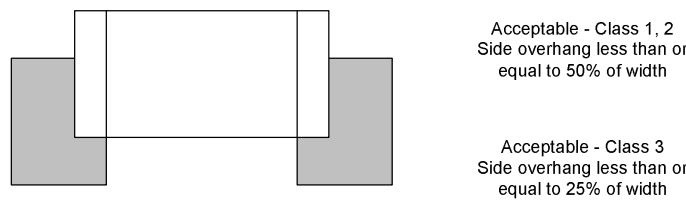

Figure 1. Example of allowable SMT placement.

SMT assembly steps include the following:

1. Placement of empty ("bare") PCBs on the assembly line.

2. Deposition of solder paste onto all SMT pads on the PCB, using stencil and/or syringe-deposition techniques.

3. Placement of SMT parts onto the appropriate pads/paste.

4. Reflow of the solder paste in a reflow oven.

Several of these steps will be briefly described. In step 2, the solder paste that is deposited onto the PCB pad patterns is a mixture of tin and other metals, solder flux to reduce

"Proceedings of the 2005 American Society for Engineering Education Conference \& Exposition Copyright (C) 2005, American Society for Engineering Education" 
oxidation of the metals, and various binders. It has a consistency resembling that of creamy peanut butter, and the reader familiar with soldering with wire solder may want to think of the paste as taking some of the wire solder and running it through a blender.

In step 4, the entire PCB + components assembly is sent through an oven that raises the temperature of the assembly above the melting point of solder, approximately $200^{\circ} \mathrm{C}$ for $\mathrm{SnPb}$ solder, and then returns it to room temperature in about 5-6 minutes.

The vast majority of electronic products are produced on a PCB that is comprised of epoxy and fiberglass. Understanding of the chemistry of the materials involved as well as their thermal characteristics is an important part of both the design and assembly steps. The author would note that two of the best overall references on component packaging are Intel's 17 chapter "Packaging Databook"3, and National Semiconductor's similar 20+ section "Packaging"4 information, which includes information on lead-free materials.

\section{DFM for SMT}

Design for manufacturability (DFM) for SMT PCB designs is widely discussed in the literature $^{56}$, since it is possible to design a circuit board that would not be cost-effective to manufacture. One of the basic requirements for DFM is that circuit board designs be available in either Gerber format ${ }^{7}$ or the newer GenCAM format ${ }^{8}$, which are two file formats that can be used and/or converted for both PCB fabrication as well as automated assembly machines.

DFM for SMT requires consideration of the following:

- Limitations of the automated equipment to be used in assembly

- Recognition of equipment clearance requirements

- Recognition of circuit board fabrication limitations, particularly spacing minimums

- Types of components used in the design, particularly the lead pitch of ICs and the height of unusually high components (lead pitch is the center-to-center distance between two adjacent terminations)

- Availability of design files that can be converted to assembly-equipment driver files

- Solder paste application method to be used

- PCB cleaning technique to be used

\section{Manufacturing with SMT}

The four steps noted in "SMT Basics" for manufacturing with SMT designs should include the following manufacturing and testing operations, either manual or automated:

1. Bare PCB testing for shorts and opens

2. PCB handling

3. Understanding of file conversions from the quasi-standard gerber PCB files to paste deposition and placement machine files.

4. Solder paste deposition, by a stenciling process or a syringe deposition system

5. Solder paste volume determination, either continual or spot-check.

6. Parts placement, which can be manual, semi-automated, or fully automated, with placement verification.

7. Reflow in an oven, which can be a batch process or a conveyorized process, and which results in the formation of the solder joints. 
8. Verification of the thermal profile the PCB is subjected to in the oven.

9. Testing of PCB functions, both specific checks during the manufacturing process, and for full functionality at completion.

While there are a variety of processes involved, various sources note that it is not out of line to say that approximately $70 \%$ of the process and product problems occurring with an electronics manufacturing line involve solder paste and the soldering process. Therefore a more detailed look at the soldering process is necessary.

The makeup of the solder paste itself is undergoing changes. The traditional metals (solid or paste) in solder used in electronics assembly are tin and lead, typically a $63-37 \%$ mix by weight. In an attempt (misguided, in this author's opinion) to minimize lead in the waste stream, the European Union has issued a directive that electronic components and assemblies may not contain lead, starting in the summer of 2006. To this end component suppliers are removing lead from the terminations of their components and solder paste formulations are being put forth that do not contain lead, and for which complete understanding does not currently exist.

Manufacturing engineers need to understand the issues that surround this change, as it will certainly impact the quality and reliability of their products. The EU recognizes this, as their directive requires elimination of lead in consumer products starting in the summer of 2006, but "high-reliability" electronic products may have an additional two years before they must be produced with no-lead solder. One major issue with this change is that the primary solders being considered to replace tin-lead are variations of a tin-silver-copper alloy, and this alloy melts approximately $35^{\circ} \mathrm{C}$ above the melting point of tin-lead. Another is the formation of tin whiskers by the pure tin used on component terminations.

The application of the solder paste to the PCB whether by stencil or syringe deposition has potential for problems. Fabrication of the stencil itself can be done with several technologies, including chemical etching and laser "etching". Each process provides its own set of plusses and minuses. Incorrect adjustment of the pressure of the squeegee on the stencil can create problems with too much or not enough paste deposited on each footprint. Alignment of stencils with the board is normally done using fiducials in the copper layer of the PCB itself, and the tolerance stackup of PCB artwork + copper fabrication + camera recognition + X-Y table motion, etc., must be recognized. This type of tolerance stackup occurs throughout the manufacturing process. Syringe deposition systems have their own tolerance issues as well as the issues that surrounding forcing a mixture of metals, flux and binders through a 0.022 " i.d. needle.

To increase the probability of a satisfactory solder joint, placement of components is not done "onto" the deposited paste, but rather "into" the paste. Therefore the downforce of the placement machine head must be carefully controlled.

The reflow process must be carefully controlled. The specific temperatures on the board as well as dwell times and ramp rates are control issues. Note that it is the temperatures on the PCB assembly itself that are the issue, not just the air temperature of the oven. The preferred temperatures on the board should follow a profile, an example of which is shown in figure 2. 


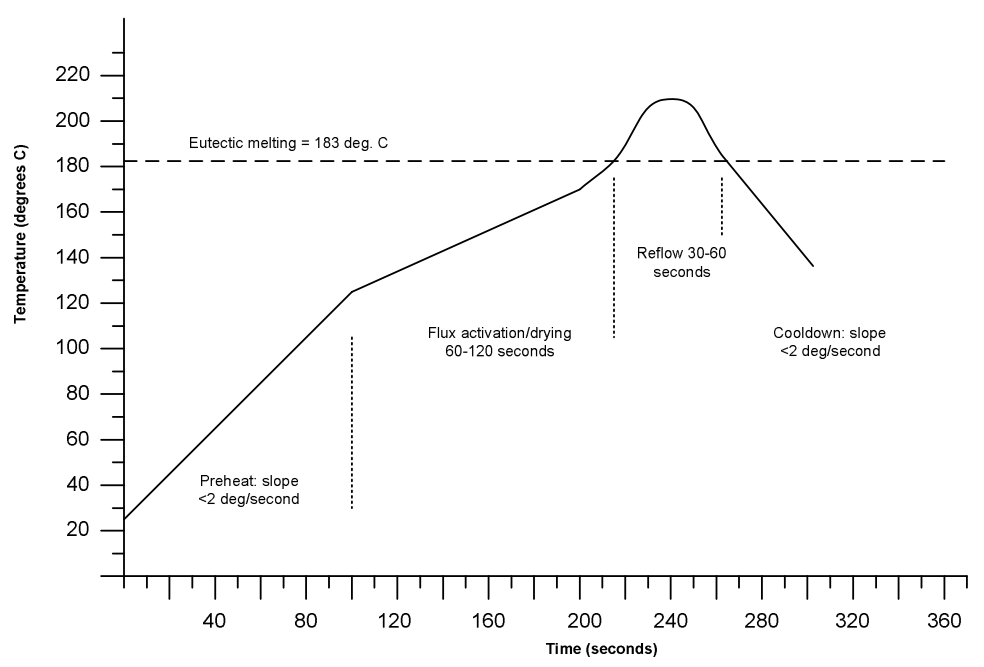

Figure 2. Temperature profile of a reflow soldering oven.

The profile shows a controlled preheat ramp, a dwell time to allow the flux to activate around $125^{\circ} \mathrm{C}$, a reflow "bump" that gets the terminations and solder paste hot enough to create acceptable solder joints, and a cool-down ramp. This profile would be measured at solder pads the surface of the PCB or component terminations. The control profile of the oven is then set to create this profile after heat transfer to the board, solder paste and components has taken place.

While a number of heating technologies are in use, including IR and vapor phase, most current ovens heat the PCB assembly using hot air convection heating, as it gives the most consistent results ${ }^{9}$. This article will discuss several techniques to accomplish this in the lab.

\section{Laboratory experiences to teach SMT manufacturing}

The author should note that while he teaches both undergraduate and graduate courses in SMT and electronic manufacturing, the information in this article is meant to describe the teaching of SMT manufacturing at the undergraduate level. To cover the topics discussed under "Manufacturing with SMT" the following laboratory topics are included:

- Testing of bare PCB for shorts and opens, using meters and a bed-of-nails system.

- Solder paste deposition by syringe deposition systems, both manual and automated.

- Solder paste volume determination with the use of a lab balance and known paste density.

- Parts placement manually, then X-Y table assisted (figure 9), then fully automated (figure $10)$, with placement verification.

- Manual soldering (figure 6) of a small PCB assembly with both discrete components and ICs.

- Reflow using both a batch oven (figure 8) and a conveyorized oven (figure 10), and which results in the formation of the solder joints.

- Verification of the thermal profile the PCB is subjected to in each oven, with the use of high temperature solder to solder a thermocouple to appropriate solder pads.

- Inspection and evaluation of solder joints to IPC standards for an appropriate class of assembly.

- Design of a basic circuit and PCB layout using the Cadence tool suite, with DFM checks of the layout. The design then will be used in the automated syringe deposition system, which is programmed accordingly by the students. 
Fume containment systems are used as appropriate in the various processes. These are recirculating filter systems

Of the processes involved in SMT assembly, it should be apparent that a thorough understanding of SMT manufacturing requires knowledge of metal joining (soldering), chemistry (flux actions, solder metals' phase diagrams, PCB laminates), heat transfer (soldering and PCB warpage), controls (reflow oven), data collection (as in any manufacturing line plus the thermal profile of the reflow oven), robotics (placement systems) and other related technologies. Thus, solder and the soldering process are the key players in success of an electronic manufacturing line. To reasonably teach SMT manufacturing requires not only the knowledge but the ability to repeat lab experiments for the students' learning. This means that at a minimum these processes should be available to the students:

- Solder paste storage at $40^{\circ} \mathrm{C}$, with solder paste replaced yearly if not used.

- Solder paste deposition by syringe, either manually or time-pressure dispensing.

- Hot air soldering with a batch oven; thermal profiling.

- Manual soldering with a soldering iron

- Manual placement of parts using a vacuum tool; X-Y table assisted placement.

- Magnified inspection of solder joints

The author believes that undergraduate students learn processes best when they are involved in them and can see both correct and incorrect results. Therefore all undergraduates learning electronic manufacturing must learn how to manually solder components on a PCB. As a side note, most contract electronic manufacturers have overruns of both bare PCBs and components that they will gladly donate to educational institutions if asked. Students can learn to solder everything from discrete components such as resistors up through fine-pitch quad flat packs (QFPs) using the information widely available both in print as well as on the world wide web $^{10,11}$. By performing soldering and evaluating the resulting solder joints they learn that creating acceptable solder joints is not trivial and they learn some of the techniques that result in both acceptable and unacceptable solder joints.

If the manufacturing course is being taught in conjunction with the teaching of electronic design and DFM, circuit boards can be designed for the manufacturing process. Some shopping on the internet will result in commercial PCB fabricators who will etch a PCB with solder mask and silk screen lettering for $\$ 30-50$.

The manual deposition of solder paste can be done with a manual syringe for $\$ 0$ since a syringe can be included with no charge with paste purchase, although volume control is strictly "by eye" with this technique. A standard time-pressure dispense system improves the repeatability of solder paste deposits, although there is still enough variation with time-pressure (\$500-\$1000) that all medium and high-volume manufacturing facilities use positive displacement volumetric dispensing techniques. The cost of positive displacement pumps usually means their use is restricted to systems that cost in excess of $\$ 8000$.

Solder paste is available with standard rosin mildly activated (RMA) flux, with watersoluble flux, and with no-clean flux. The author suggests starting with RMA flux since it is more active than no-clean flux and therefore will still allow the creation of acceptable solder joints 
even if PCB and component handling is not as careful as it should be. The RMA flux residue can be cleaned off of the boards with standard rubbing or ethyl alcohol, although all precautions must be used since this is a flammable solvent. Paste kept refrigerated will have a shelf life of 6 months to one year, whereas at room temperature paste manufacturers suggest a shelf life for paste syringes of 1-3 months. It is important to note that most paste currently available contains lead and therefore MUST NOT be thrown away into the waste stream. It must be recycled properly.

Placement of parts can be done with tweezers or toothpicks with poster putty on them. It is important for students to note that any contaminants on the component terminations increase the probability of poor solder joints, therefore components should not be handled by fingers on their leads or terminations. A step up from tweezers and toothpicks are the vacuum tools available for $\$ 50-100$, and beyond that vacuum tools attached to X-Y arms that significantly increase the ease and accuracy of placement. These are available in the $\$ 3000-\$ 7000$ range. If a fully automated placement system is desired, costs start at $\$ 20 \mathrm{~K}$ and rapidly increase to over $\$ 100 \mathrm{~K}$, although the author has had some success in getting equipment like this donated since the companies can then claim their charity against their taxes!

Once parts are placed in paste, progressing beyond hand soldering requires an oven. If a truly low-budget approach is desired, a toaster oven with a thermal probe can be used successfully $^{12}$. One step above this is to have the electronic engineering students design a microprocessor or PC control system for a toaster oven. This still keeps the cost of a batch reflow oven below $\$ 500$. If a program has additional funds, stand-alone commercial batch reflow ovens with adjustable profiles are available for around $\$ 4000$ from some of the suppliers listed at the end of this paper. Programs that desire to teach reflow soldering as it is typically done in industry can purchase commercial conveyorized reflow ovens starting around $\$ 8000$.

Inspection of the resulting solder joints, regardless of the manner of soldering, requires some type of magnification. The author's experience is that magnifiers are the wrong thing to save money on. Power of $5 \mathrm{X}$ to $10 \mathrm{X}$ are sufficient for most work, but the inexpensive "reading glass" type of magnifier is frequently of such poor quality as to hamper the students' abilities to determine the quality of their solder joints. Inspection also requires that the instructor define the class of electronic product the work is supposed to result in. As discussed earlier, not only do the three classes have different requirements for component locations, but also for solder joint inspection criteria.

Each class has its own inspection criteria for solder joints. These include the amount of solder that makes up a solder joint as well as the location of the solder fillet relative to the pad on the PCB and the component termination. As would be expected, the criteria for solder joints are much stricter in class 3 assemblies ${ }^{13}$.

\section{Examples}

Following are figures $3 \& 4$, which show examples of equipment in use in the Purdue ECET labs, and suitable for undergraduate education.

"Proceedings of the 2005 American Society for Engineering Education Conference \& Exposition Copyright ( 2005 , American Society for Engineering Education" 


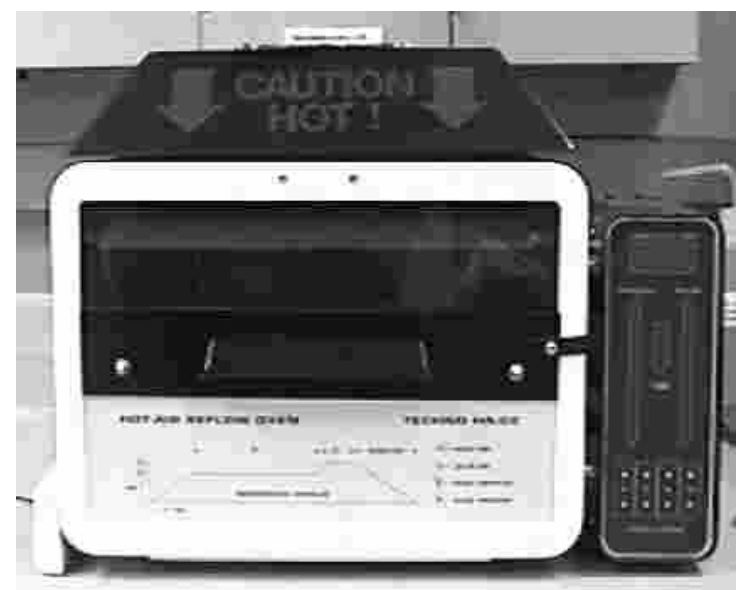

Figure 3. Batch reflow oven

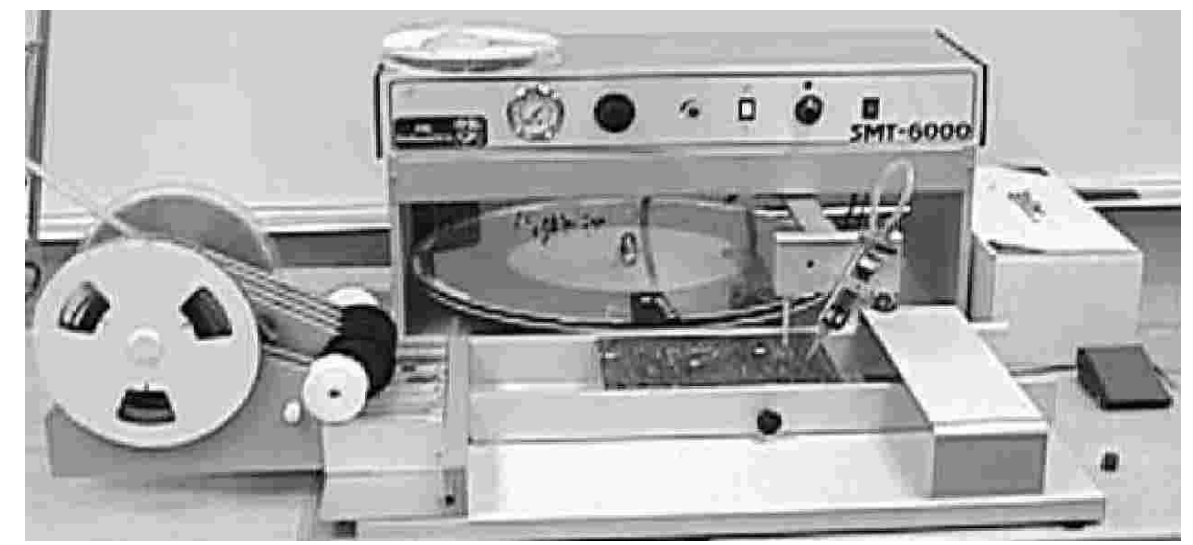

Figure 4. Manual X-Y arm assisted placement station.

As an example of what can be accomplished by undergraduate students who are new to electronic assembly and manufacturing, figure 5 shows a small digital voltmeter project that was designed by a $4^{\text {th }}$ semester student in ECET, and completely soldered by hand with a standard Weller temperature-controlled soldering iron. The PCB fabrication was done by Advanced Circuits in Boulder, CO, (www.4pcb.com) at a student cost of \$33 (spring 2005 cost) plus shipping, with a turn around time of 5 days from the receipt of e-mailed Gerber files. 


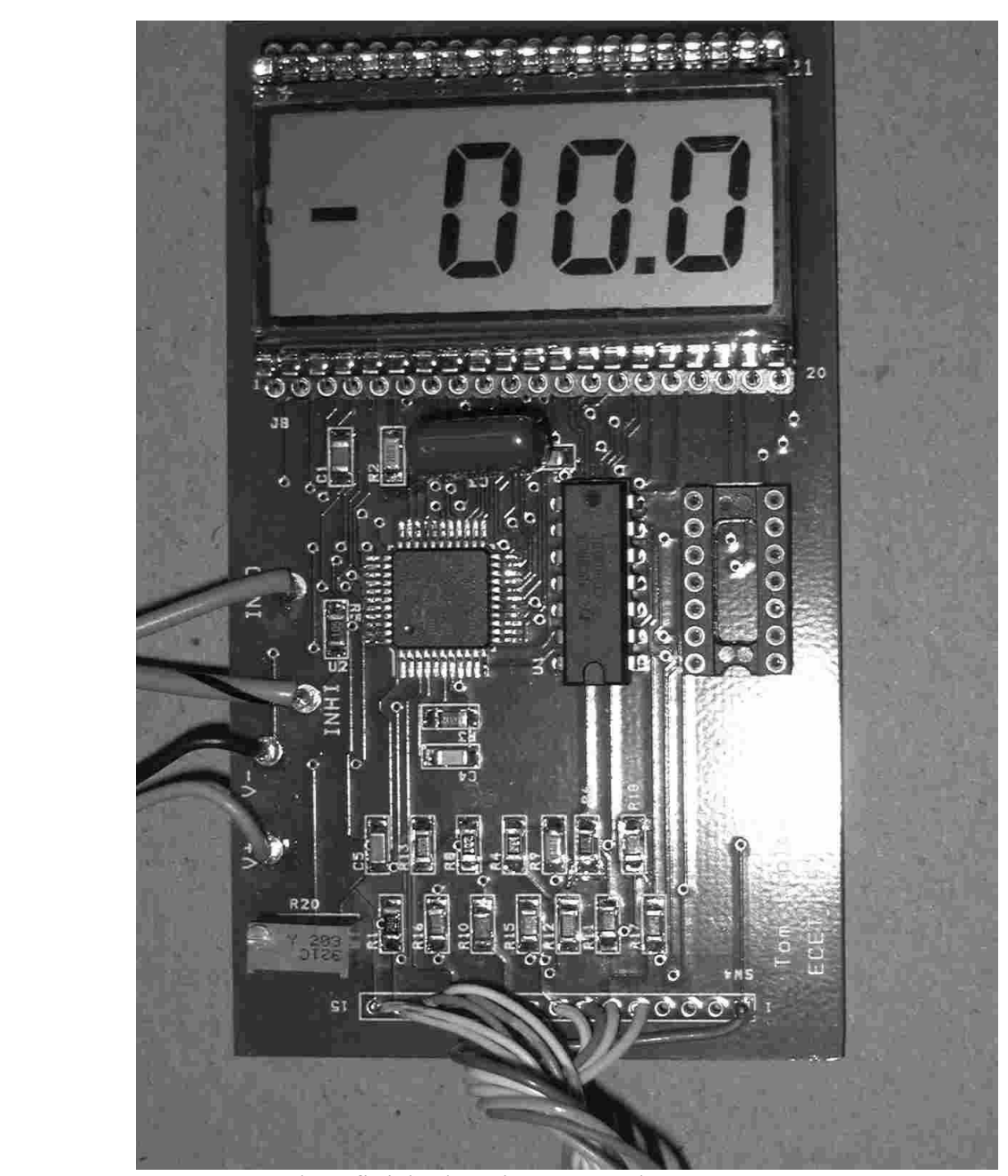

Figure 5. Student finished project example.

The circuit board in figure 6 shows a mix of both SMT and THT components, indicating that undergraduate students can successfully work with both types of technologies.

Hopefully these figures will help with understanding the use of some of the equipment discussed in the article.

\section{Suppliers}

Note that these suppliers are not recommended by the author, and this is not a complete list. The names are provided merely as a place to start if the reader is interested in investigating the purchase of the types of equipment discussed in the article. Some of these suppliers sell through distributors and some sell direct, although the author has found all of them willing to answer questions and discuss their products over the phone with potential educational purchasers.

Suppliers of solder paste include:

AmTech, www.amtechinc.com

Indium, www.indium.com

Kester, www.kester.com

"Proceedings of the 2005 American Society for Engineering Education Conference \& Exposition Copyright (C) 2005, American Society for Engineering Education" 
Suppliers of manual assembly tools include:

Techni-tool, www.technitool.com

Digi-key, www.digikey.com

Suppliers of semi-automated and small automated placement equipment, and batch and small conveyorized reflow ovens include:

Automated Production Systems (APS), www.apsgold.com

Mann-Corp, www.manncorp.com

All pictures and drawings in this paper taken or created by the author.

\section{References}

1 -----, "Flip Chip Packaging Services". Available at http://www-

306.ibm.com/chips/products/interconnect/products/flipchip.html.

2 -----, "Ceramic Chip Carriers". Available at http://www-

3.ibm.com/chips/technology/makechip/interconnect/4.html.

3 -----, "Intel Packaging Databook". Available at http://www.intel.com/design/packtech/packbook.htm .

4 -----, "Packaging". Available at http://www.national.com/packaging/ .

${ }^{5}$ Shina, S.; Concurrent Engineering and Design for Manufacture of Electronic Products. Van Nostrand Reinhold, 1991, New York.

${ }^{6}$ Ferguson, J.; "Shifting Methods: Adopting a Design for Manufacture Flow". Available at http://www.mentor.com

7 -----; “Gerber Data Format". Available at http://www.apcircuits.com/resources/information/gerber_data.html

8 ----; Generic GenCAM Requirements. Available at http://gencam.ipc.org

9 -----; “Reflow Technology Handbook - Chapter 6, Reflow Oven Convection Methods". Available at http://www.research-intl.com/reflowtechbook.htm . Research International, Ronkonkoma, NY.

${ }^{10}$ Winstanley, A.; "The Basic Soldering Guide”. Available at http://www.epemag.wimborne.co.uk/solderfaq.htm

11 ----; "Hand Soldering Tutorial for Fine Pitch QFP Devices". Application note AN114, available at

http://www.silabs.com/products/docfinder.asp.

12 Maxon, K.; "Have You Seen My New Soldering Iron?”. Available at http://www.seattlerobotics.org/encoder/200006/oven_art.htm.

13 ----; “Acceptability of Electronic Assemblies". IPC document IPC-A-610, rev. C. IPC, January 2000, Northbrook, IL..

Biographical Information

Glenn R. Blackwell, P.E., Associate Professor, Electrical Engineering Technology

Purdue University, Knoy 1415, W. Lafayette, IN 47907-1415, phone: 317-494-7726, blackwell@purdue.edu

Glenn Blackwell currently is teaching in the areas of project courses, surface mount technology (SMT), and electronic manufacturing. He has spent two sabbaticals in industry working with SMT.

"Proceedings of the 2005 American Society for Engineering Education Conference \& Exposition Copyright (C) 2005, American Society for Engineering Education" 